\title{
Caseous calcification of the mitral annulus - the complementary role of computed tomography and transthoracic echocardiogram
}

\author{
Illona Michałowska ${ }^{1 \mathrm{E}}$, Piotr Szymański2 ${ }^{2 A}$, Paweł Kwiatek ${ }^{1 \mathrm{~B}}$, Michał Spałek ${ }^{3,4 \mathrm{~B}}$, Mariusz Furmanek ${ }^{5 D}$, \\ Piotr Zieliński ${ }^{6 F}$, Sara Kochańska ${ }^{7 C}$, Magdalena Lipczyńska ${ }^{6 D}$ \\ 'Department of Radiology, Institute of Cardiology, Warsaw, Poland \\ ${ }^{2}$ Department of Acquired Cardiac Defects, Institute of Cardiology, Warsaw, Poland \\ ${ }^{3}$ Department of Diagnostic Imaging, Świętokrzyskie Oncology Centre, Kielce, Poland \\ ${ }^{4}$ Jan Kochanowski University, Faculty of Medicine and Health Sciences, Kielce, Poland \\ ${ }^{5}$ Radiology and Diagnostic Imaging, Medical Centre for Postgraduate Education, Warsaw, Poland \\ ${ }^{6}$ Department of Congenital Cardiac Defects, Institute of Cardiology, Warsaw, Poland \\ 7Department of Radiology, Health Care Centre, Ostrowiec Świętokrzyski, Poland
}

\begin{abstract}
Purpose: Caseous calcification is a relatively uncommon variant of calcification of the mitral annulus. The purpose of the study was to assess characteristic radiological features of caseous calcification of the mitral annulus (CCMA) using computed tomography (CT) and compare the usefulness of CT and transthoracic echocardiogram (TTE) in a diagnosis of CCMA.

Material and methods: Seventeen patients with CCMA, who underwent TTE and CT, were analysed. The following features of CCMA were evaluated: location, size, attenuation, enhancement after contrast administration, and margins.

Results: In all cases TTE visualised an echo-dense structure with an irregular appearance involving the mitral valve annulus. In five cases the acoustic shadowing artefact was visible, and in four cases the mass contained central areas of echolucency. Eleven patients had valve disease.

On CT CCMA appeared as a round mass in one case, in 10 cases as an oval mass, and in six patients it had a semilunar shape.

In all cases on unenhanced CT, CCMA appeared as a hyperdense mass. On enhanced CT, CCMA in 10 cases (58.8\%) had a hypodense centre, and in 7 seven (41.2\%) it had a hyperdense centre without enhancement after contrast administration. A hyperdense rim was observed in all cases except one patient.

Conclusions: In cases of the atypical appearance of CCMA on TTE, CT can lead to a definitive diagnosis. The combination of unenhanced CT and after IV contrast administration scans allows for recognition and distinction of CCMA from other pathologies, while TTE allows for assessment of additional valve dysfunction.

Key words: computed tomography (CT), caseous calcification of the mitral annulus, transthoracic echocardiogram.
\end{abstract}

\section{Introduction}

Calcification of the mitral annulus (MAC) is a chronic, degenerative process, which occurs in the elderly, particularly in women [1]. In younger patients, MAC is con- nected with end-stage renal disease or metabolic disorders [2]. MAC has rarely been found in patients with Barlow's disease [3] and Marfan's syndrome [4].

Caseous calcification of the mitral annulus (CCMA) or liquefaction necrosis is a relatively uncommon variant

\section{Correspondence address:}

Dr. Ilona Michałowska, Department of Radiology, Institute of Cardiology, 42 Alpejska St., 04-628 Warsaw, Poland, e-mail: ilonamich@wp.pl

Authors' contribution:

A Study design · B Data collection · C Statistical analysis · D Data interpretation · E Manuscript preparation · F Literature search · G Funds collection 
of MAC. Deluca et al. reported the prevalence of CCMA in the entire population as $0.068 \%$ and $0.64 \%$ in patients with MAC [1].

The precise mechanism of caseous transformation of CCMA is not well understood [1]. Spontaneous resolution of CCMA and the transformation back to MAC have been reported in the literature $[1,2,5]$.

Typically, CCMA appears as a round mass with an echolucent centre made up of a putty-like admixture of fatty acids, cholesterol, and calcium, located in the posterior mitral annulus, but it may also involve the entire annulus and extend to the mitral apparatus [6].

CCMA is mostly benign and incidentally diagnosed; however, it may be associated with mitral valvular dysfunction, conduction abnormalities, or systemic embolisation $[2,7-9]$.

Typical location and imaging features of transthoracic echocardiogram (TTE) are usually sufficient to confirm the diagnosis of CCMA.

However, in some cases the diagnosis of CCMA may be challenging and require differentiation from cardiac tumours, myocardial abscesses, and other abnormalities occurring in the atrioventricular groove. Misdiagnosed CCMA leads, in some cases, to unnecessary surgery.

On the other hand, in relation to the increasing number of cardiac computed tomography (CT) examinations, CCMA may be accidentally discovered during an examination and the radiologist needs to be familiar with its appearance.

The purpose of this study was to assess characteristic radiological features of caseous calcification of the mitral annulus using multislice computed tomography and to compare the usefulness of CT and TTE in the diagnosis of CCMA.

\section{Material and methods}

In this study, we retrospectively analysed 17 cases of CCMA, which were recognised by CT between 2011 and 2017.

All patients had had a standard transthoracic echocardiography. Two of them had additionally had tran-

Table 1. Clinical characteristics of patients

\begin{tabular}{|l|c|c|}
\hline Age $(y)($ mean \pm SD) & $72 \pm 0.7$ & Percentage \\
\hline Women/men & $15 / 2$ & $88.2 / 11.8$ \\
\hline History & & \\
\hline Hypertension & 11 & 64.7 \\
\hline Atrial fibrillation & 7 & 41.2 \\
\hline Coronary heart disease & 6 & 35.3 \\
\hline Diabetes mellitus & 5 & 29.4 \\
\hline Chronic renal failure & 1 & 0.6 \\
\hline
\end{tabular}

soesophageal echocardiography as a routine procedure in qualifying for transcatheter aortic valve implantation (TAVI). The two-dimensional technique was used to demonstrate the localisation and density of the pathologic structure. With colour, pulse, and continuous Doppler, we searched for accompanying valve diseases.

Computed tomography (CT) examinations were performed with a dual-source scanner (Somatom Flash, Siemens Medical Solutions, Erlangen, Germany) with the use of retrospective ECG gating, with beam collimation of $64 \times 0.6 \mathrm{~mm}, 128$ slices, a gantry rotation time of $280 \mathrm{~ms}$, and tube voltage $100-120 \mathrm{kV}$ depending on the patient's body mass.

Unenhanced scans and scans after the IV injection of contrast medium were obtained.

Highly iodinated contrast material $(\geq 350 \mathrm{mg} / \mathrm{ml}$ ) was administered in the antecubital vein in the amount of $80-100 \mathrm{ml}$ at a flow rate of $5 \mathrm{ml} / \mathrm{s}$, followed by a $30-\mathrm{ml} \mathrm{sa-}$ line chaser. Image acquisition was initiated $4 \mathrm{~s}$ after reaching 100 H.U. threshold enhancement within the region of interest placed in the ascending aorta.

The following features of CCMA were evaluated: location, size, attenuation, enhancement after contrast administration, and margins.

Eleven patients $(64.7 \%)$ were referred for CT with a suspicion of cardiac tumours based on TTE results; in one patient CCMA diagnosis was established incidentally based on TTE, and CT was performed to confirm the diagnosis; in five cases CCMA was detected incidentally during coronary CT angiography in patients with a suspicion of coronary artery disease.

Descriptive statistics was used to provide a summary of the data. Frequency and percentages were reported for categorical variables; summary statistics, including the mean, $\mathrm{SD}$, and range were calculated.

\section{Results}

Seventeen patients with CCMA were analysed ( 15 women and two men, with an age range from 52 to 91 years and mean age of $72 \pm 0.7$ years). The clinical characteristics of the patients are shown in Table 1.

In all cases, the two-dimensional echocardiography visualised an echo-dense structure with an irregular appearance involving the mitral valve annulus (Figure 1). In five (29.4\%) cases the acoustic shadowing artefact was visible. In four $(23.5 \%)$ cases the mass contained central areas of echolucency with no flow on colour Doppler examination (Figure 2). In 13 (76.5\%) patients a periannular mass was localised at the posterior annular region of the mitral valve, in four (23.5\%) patients it involved other segments of the mitral annulus - the lateral part or the entire ring. In $10(58.8 \%)$ cases, the mass also included the mitral leaflet. In one case (5.9\%), it extended the mitral apparatus, and in one case (5.9\%) the atrioventricular groove. Additionally, we found at least moderate valve 


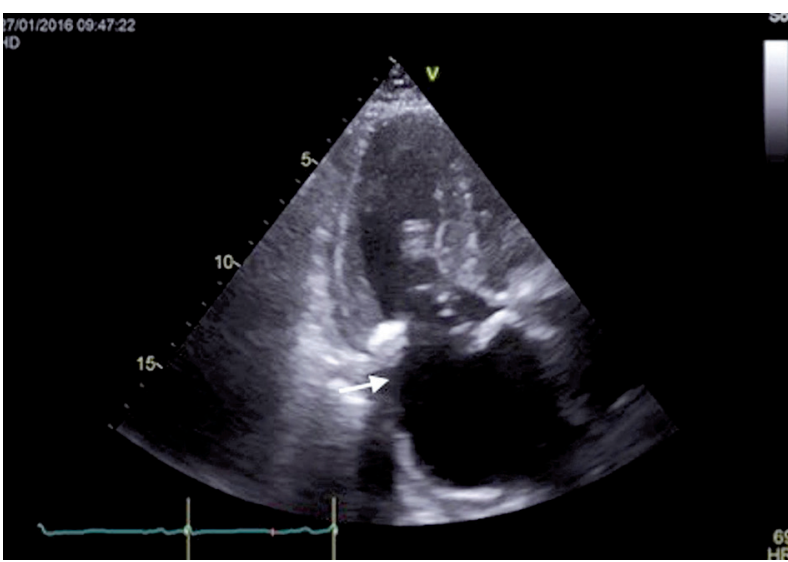

Figure 1. Two-dimensional echocardiogram, in the apical 3-chamber view, a calcific mass attached to the mitral annulus with acoustic shadowing (arrow)

disease in $11(64.7 \%)$ examined patients. Only in one patient $(5.9 \% \%)$ was CCMA recognised based on TTE and confirmed by CT.

On CT CCMA appeared as a round mass in one case, in $10(58.8 \%)$ cases as an oval mass, and in six (35.3\%) patients it had a semilunar shape. In all patients who were referred for CT with a suspicion of cardiac tumours, CCMA appeared as an oval mass, except for one case where it was a round mass.

In 15 (88.2\%) patients, CCMA was located in the posterior mitral annulus; in two cases, CCMA involved the anterior part of the mitral annulus. In 10 cases, CCMA involved the base of the posterior leaflet of the mitral valve. In one case, it extended to the chordae tendineae, and in one case the mass was bulging into the left ventricular cavity.

In all cases on unenhanced CT, CCMA appeared as a hyperdense mass (Figure 3A, 4A). On CT after contrast

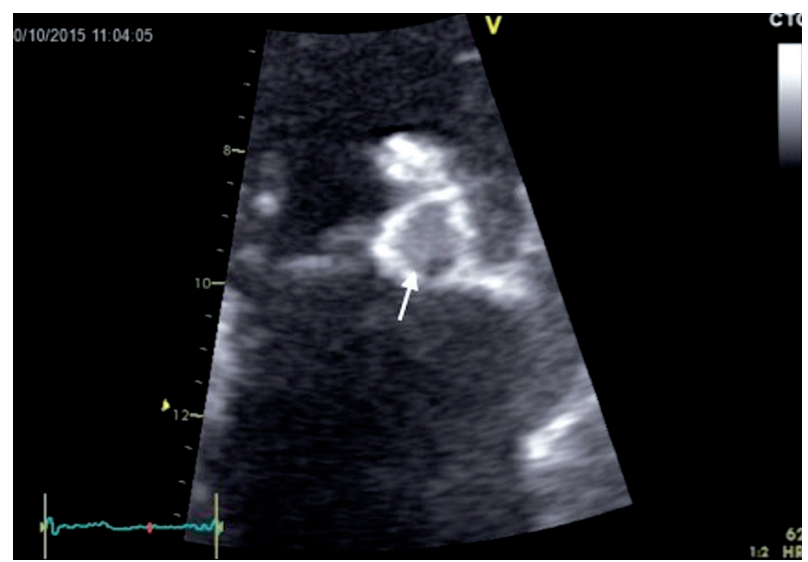

Figure 2. Two-dimensional echocardiogram, in the apical 4-chamber view round echo-dense mass with smooth borders situated in the periannular region, with no acoustic shadowing artefact and central areas of echolucency resembling liquefaction (arrow)

administration in 10 cases, (58.8\%) CCMA had a hypodense centre (Figure 3B) and in seven (41.2\%) it had a hyperdense centre (Figure $4 \mathrm{~B}$ ).

Table 2 shows the locations of CCMA and its appearance on CT and TTE.

The mean attenuation value of the central part of CCMA on unenhanced scans was $231.42 \pm 175.56$ H.U. (attenuation value range from 39 H.U. to 512 H.U.), with four patients with mean attenuation values below $100 \mathrm{H}$.U.

The mean attenuation value of the central part of CCMA after IV contrast material administration was $230.23 \pm 155.16$ H.U. (attenuation value ranged from 41 H.U. to 544 H.U.). We did not observe significant enhancement after IV contrast agent administration. A hyperdense rim was observed in all cases with the exception of one patient. The mean size of CCMA was $26 \pm 12.51 \mathrm{~mm}$ (range from 10 to $64 \mathrm{~mm}$ ).
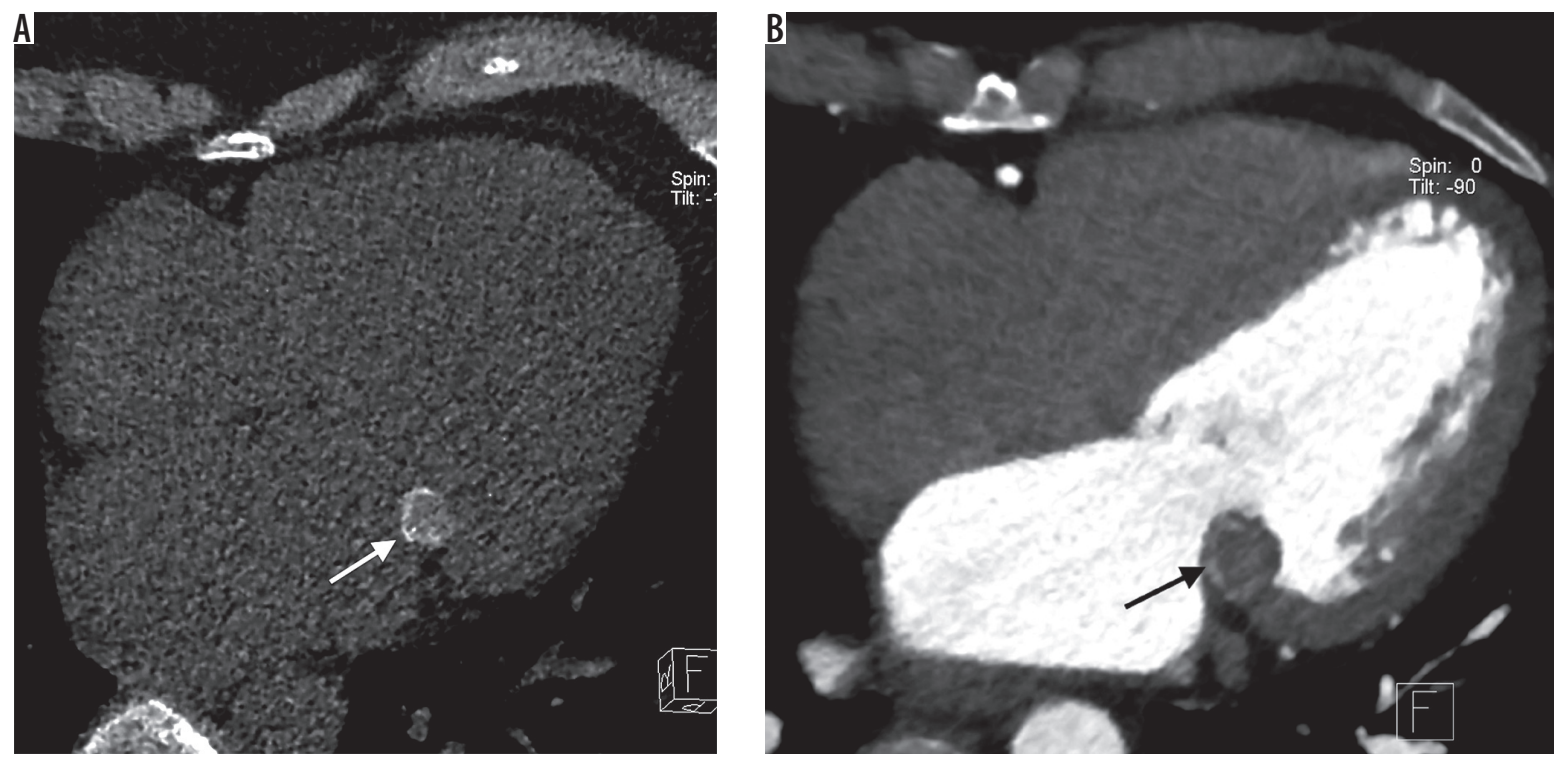

Figure 3. Cardiac (T; A) unenhanced (T, B) contrast enhanced (T, 4-chamber views show a round hypodense mass with peripheral linear calcification (arrows) 

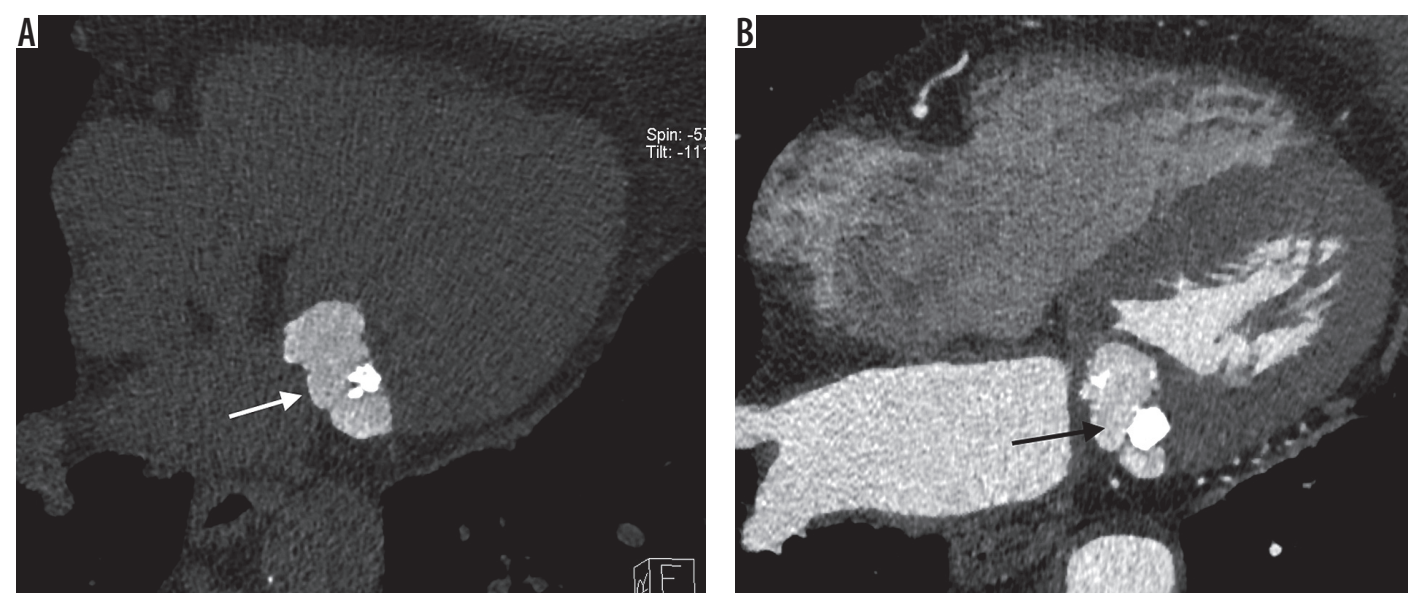

Figure 4. Cardiac (T; A) unenhanced (T, B) contrast enhanced (T, 4-chamber views show an oval hyperdense mass with calcification (arrows) in the left atrioventricular groove

Table 2. The locations of CCMA and its appearance on CT and TTE

\begin{tabular}{|c|c|c|c|c|c|c|}
\hline $\begin{array}{l}\text { Patient } \\
\text { number }\end{array}$ & Sex & $\begin{array}{c}\text { TTE } \\
\text { localisation }\end{array}$ & TTE density & $\begin{array}{c}\text { TTE } \\
\text { valvular disease }\end{array}$ & $\begin{array}{c}\text { CT } \\
\text { localisation }\end{array}$ & $\begin{array}{c}\text { CT } \\
\text { density }\end{array}$ \\
\hline 1 & $\mathrm{~F}$ & Posterior ring & $\begin{array}{l}\text { Hyperdense with } \\
\text { hypodense centre }\end{array}$ & $\begin{array}{l}\text { Moderate MR, } \\
\text { moderate TR }\end{array}$ & $\begin{array}{c}\text { Posterior } \\
\text { ring, attached } \\
\text { posterior leaflet }\end{array}$ & $\begin{array}{c}\text { Centrally hypodense, } \\
\text { peripherally } \\
\text { calcified mass }\end{array}$ \\
\hline 2 & $\mathrm{~F}$ & $\begin{array}{l}\text { Posterior ring, } \\
\text { posterior leaflet }\end{array}$ & $\begin{array}{l}\text { Hyperdense with } \\
\text { hypodense centre }\end{array}$ & Mild MR, mild AR & $\begin{array}{l}\text { Posterior ring, } \\
\text { posterior leaflet }\end{array}$ & $\begin{array}{c}\text { Hyperdense with } \\
\text { peripherally calcified }\end{array}$ \\
\hline 3 & $\mathrm{~F}$ & $\begin{array}{l}\text { Posterior ring, } \\
\text { atrioventricular groove }\end{array}$ & Hyperdense & Mild MR & $\begin{array}{l}\text { Posterior ring, } \\
\text { LV myocardium }\end{array}$ & $\begin{array}{c}\text { Hypodense with } \\
\text { peripherally calcified }\end{array}$ \\
\hline 4 & $\mathrm{~F}$ & Posterior ring & $\begin{array}{c}\text { Hyperdense, } \\
\text { acoustic shadowing }\end{array}$ & $\begin{array}{l}\text { Moderate MR, } \\
\text { mild AR }\end{array}$ & $\begin{array}{c}\text { Posterior ring, posteriori leaflet, } \\
\text { LV myocardium }\end{array}$ & $\begin{array}{c}\text { Hyperdense, } \\
\text { peripherally calcified }\end{array}$ \\
\hline 5 & $\mathrm{~F}$ & $\begin{array}{l}\text { Posterior ring, } \\
\text { posterior leaflet }\end{array}$ & Hyperdense & Mild MR & $\begin{array}{l}\text { Posterior ring, } \\
\text { posterior leaflet }\end{array}$ & $\begin{array}{l}\text { Centrally hyperdense, } \\
\text { peripherally calcified }\end{array}$ \\
\hline 6 & $\mathrm{~F}$ & Lateral ring & Hyperdense & $\begin{array}{l}\text { Mild MR, mild AR, } \\
\text { moderate TR }\end{array}$ & Posterior ring & $\begin{array}{c}\text { Hyperdense, } \\
\text { peripherally calcified }\end{array}$ \\
\hline 7 & $M$ & Whole ring & $\begin{array}{l}\text { Hyperdense with } \\
\text { acoustic shadowing }\end{array}$ & Mild MR, severe AS & $\begin{array}{l}\text { Posterior } \\
\text { ring }\end{array}$ & $\begin{array}{l}\text { Centrally hypodense, } \\
\text { peripherally calcified }\end{array}$ \\
\hline 8 & $\mathrm{~F}$ & $\begin{array}{l}\text { Lateral ring, both leaflets, } \\
\text { subvalvular apparatus }\end{array}$ & Hyperdense & Mild MR, mild TR & $\begin{array}{c}\text { Posterior ring posterior leaflet, } \\
\text { right AV groove }\end{array}$ & $\begin{array}{l}\text { Hyperdense, partially } \\
\text { peripherally calcified }\end{array}$ \\
\hline 9 & $\mathrm{~F}$ & $\begin{array}{l}\text { Posterior ring, } \\
\text { posterior leaflet }\end{array}$ & Hyperdense & $\begin{array}{l}\text { Moderate MR, } \\
\text { mild Al, mild TR }\end{array}$ & $\begin{array}{l}\text { Posterior ring, } \\
\text { posterior leaflet }\end{array}$ & $\begin{array}{l}\text { Centrally hypodense, } \\
\text { peripherally calcified }\end{array}$ \\
\hline 10 & $M$ & $\begin{array}{l}\text { Posterior ring, } \\
\text { posterior leaflet }\end{array}$ & $\begin{array}{l}\text { Hyperdense with } \\
\text { hypodense centre }\end{array}$ & $\begin{array}{l}\text { Moderate MR, } \\
\text { mild AR, mild TR }\end{array}$ & Posterior leaflet & $\begin{array}{l}\text { Centrally hypodense, } \\
\text { peripherally calcified }\end{array}$ \\
\hline 11 & $\mathrm{~F}$ & $\begin{array}{l}\text { Posterior ring, } \\
\text { posterior leaflet }\end{array}$ & Hyperdense & Moderate MR & $\begin{array}{l}\text { Posterior ring, } \\
\text { posterior leaflet }\end{array}$ & $\begin{array}{c}\text { Hyperdense, } \\
\text { peripherally calcified }\end{array}$ \\
\hline 12 & $\mathrm{~F}$ & Posterior ring & $\begin{array}{l}\text { Hyperdense with } \\
\text { hypodense centre }\end{array}$ & $\begin{array}{c}\text { Moderate MS, } \\
\text { mild MR, severe AS }\end{array}$ & $\begin{array}{l}\text { Posterior ring, } \\
\text { LV myocardium }\end{array}$ & $\begin{array}{c}\text { Hypodense, } \\
\text { peripherally calcified }\end{array}$ \\
\hline 13 & $\mathrm{~F}$ & $\begin{array}{c}\text { Whole ring, } \\
\text { posterior leaflet }\end{array}$ & $\begin{array}{c}\text { Hyperdense, } \\
\text { acoustic shadowing }\end{array}$ & Mild MR, severe AS & $\begin{array}{c}\text { Whole ring, posterior leaflet, } \\
\text { anterior ring }\end{array}$ & $\begin{array}{c}\text { Hyperdense, } \\
\text { peripherally calcified }\end{array}$ \\
\hline 14 & $\mathrm{~F}$ & Posterior ring & Hyperdense & Mild MR & Posterior ring & $\begin{array}{c}\text { Hypodense, } \\
\text { peripherally calcified }\end{array}$ \\
\hline 15 & $\mathrm{~F}$ & $\begin{array}{l}\text { Posterior ring, } \\
\text { posterior leaflet }\end{array}$ & $\begin{array}{c}\text { Hyperdense, } \\
\text { acoustic shadowing }\end{array}$ & $\begin{array}{c}\text { Moderate MR, severe } \\
\text { AS, moderate TR }\end{array}$ & $\begin{array}{l}\text { Posteriori ring, } \\
\text { posterior leaflet }\end{array}$ & Hypodense \\
\hline 16 & $\mathrm{~F}$ & $\begin{array}{l}\text { Posterior ring, } \\
\text { posterior leaflet }\end{array}$ & $\begin{array}{c}\text { Hyperdense, } \\
\text { acoustic shadowing }\end{array}$ & Mild MR, severe AS & Whole ring & $\begin{array}{c}\text { Hypodense, } \\
\text { with calcifications }\end{array}$ \\
\hline 17 & $\mathrm{~F}$ & $\begin{array}{c}\text { Posterior ring, } \\
\text { posterior leaflet }\end{array}$ & Hyperdense & Mild MR & $\begin{array}{c}\text { Posteriori ring } \\
\text { posteriori leaflet }\end{array}$ & $\begin{array}{c}\text { Hypodense } \\
\text { with calcification }\end{array}$ \\
\hline
\end{tabular}

AS - aortic stenosis, MR - mitral regurgitation, Al - aortic insufficiency, TR - tricuspid regurgitation 
One patient had had aortic valve replacement due to severe aortic stenosis (AS), one had had aortic and mitral valve replacement due to severe AS and moderate mitral regurgitation (MR), and two had had the TAVI procedure. No one was operated on only for CCMA. The diagnosis of CCMA was verified histologically in one patient who underwent cardiac surgery.

\section{Discussion}

Caseous calcification of the mitral annulus is an uncommon variant of mitral annulus calcification (MAC). The prevalence of MAC in echocardiographic studies was $10.6 \%$ of the population. Among these cases CCMA was found in $0.63 \%$ to $0.64 \%$, which means that CCMA is found in $0.06-0.07 \%$ of the population $[1,2]$. Deluca found 14 patients with CCMA among 20.468 consecutive patients included in the study [1]. The largest reported study of CCMA is based on echocardiography and includes 18 patients with CCMA [10]. The CT and MRI studies are solely based on case reports. According to our knowledge, we present the largest series of CCMA cases diagnosed by CT and echocardiography. In most cases, CCMA is an incidental finding during echocardiography, and echocardiographic characteristic features are sufficient for proper diagnosis. On TTE, CCMA often appears as a round or oval, echogenic mass with a central area of echolucency, with smooth borders, without acoustic shadowing behind the mass, and it is localised into the posterior mitral annulus [10]. The recognition of CCMA by TTE may be difficult in patients with limited acoustic viewing, a poor quality of echocardiography images, or an atypical appearance. Such patients require other imaging modalities such as MRI or CT. In contrast to other studies, in most of our cases the appearance of CCMA in echocardiography was not characteristic. In 13 (76.5\%) echocardiograms, we did not find the typical central area of echolucency resembling liquefaction. In five cases (29.4\%), the mass created an acoustic shadowing, which is a hallmark of MAC. Therefore, in the majority of our cases TTE was not sufficient to confirm the diagnosis, and we considered $\mathrm{CT}$ as a second diagnostic tool.

On unenhanced CT, CCMA appears as a hyperdense oval or crescent-shaped mass with a calcified rim, located in the posterior ring of the mitral valve. In some cases, it extends over the anterior ring and into the left ventricular myocardium, mostly attached to the posterior leaflet of the mitral valve. After contrast administration, CCMA appears as a hypo-, iso-, or hyperdense mass without enhancement.

CT features of CCMA, especially unenhanced images, are characteristic and CT imaging can lead to a definitive diagnosis. Cardiac MR is considered the technique of choice in the diagnosis of CCMA. However, access to cardiac MR may be limited and CT is a widely available method and seems to be sufficient to recognise CCMA.
CCMA may sometimes be associated with mitral valve dysfunction. Most often it causes mitral regurgitation and is less likely to cause mitral stenosis [11]. The extension of CCMA in the mitral ring involving mitral leaflets may be precisely assessed by CT, but assessment of the mitral valve function is limited on CT. TTE is the method of choice in the assessment of valvular function. In our study, we found at least moderate valvular heart disease in 11 (65\%) patients. The most frequent was mitral regurgitation. Severe valvular dysfunction is the current indication for surgical intervention.

CCMA is mostly a benign finding, but it may be a potentially serious condition causing cerebral stroke. Several studies reported a connection between mitral annular calcification and stroke $[8,12,13]$. The mechanism of stroke is unclear. Embolisation of small, calcified parts and thrombus formations of CCMA are considered as possible causes of stroke [12]. The size, mobility, and location of CCMA may be factors increasing the incidence of cerebral stroke [12]. In our study, in one patient an embolism of the retinal artery was associated with CCMA.

Computed tomography allows for a precise description of the size, location, and extent of calcifications of CCMA; TTE allows for better visualisation of CCMA mobility.

In some cases, mitral annular calcification requires differentiation with caseous calcifications. MAC is usually seen as a C-, J-, U-, or O-shape around the mitral valve with coarse structure and hyperdense attenuation, and it seldom mimics a mass [14]. The appearance of CCMA is focal with an ovoid mass-like with more homogeneous attenuation than MAC [15]. "Bone windows" of CT allow better recognition of the caseous nature of MAC [15]. Some authors report misdiagnoses of CCMA as cardiac tumours and abscesses if the diagnosis is based only on echocardiography [10]. CCMA requires differentiation from infected mitral calcification, calcified tumours, a dilated coronary sinus, a large aneurysm of the circumflex coronary artery, and enlarged lymph nodes $[1,16,17]$.

Misdiagnosis of CCMA as a tumour, abscess, or aneurysm may result in unnecessary exploratory cardiotomy.

The clinical context is essential for establishing the correct diagnosis.

In our study, 11 patients were referred for CT examination with a suspicion of cardiac tumour by TTE. CCMA requires differentiation from other left atrial masses such as myxoma, haemangioma, and leiomyosarcoma [2]. Hyperattenuation on unenhanced CT without enhancement, after contrast administration, is typical of CCMA and allows for easy differentiation from other cardiac masses. Currently, conservative medical management is suggested for CCMA without severe mitral valve dysfunctions [18]. Caseous mitral annular calcification may create a diagnostic dilemma, but knowledge about characteristic imaging features leads to a correct diagnosis. 
The limitation of this work is the small group of CCMA patients. However, the study is one of the largest in the literature.

\section{Conclusions}

In cases of the atypical appearance of CCMA on TTE, CT can lead to a definitive diagnosis.
The combination of unenhanced CT and after IV contrast administration scans allows for recognition and distinction of CCMA from other pathologies, while TTE allows for assessment of additional valve dysfunction.

\section{Conflict of interest}

The authors report no conflict of interest.

\section{References}

1. Deluca G, Correale M, Ieva R, et al. The incidence and clinical course of caseous calcification of the mitral annulus: a prospective echocardiographic study. J Am Soc Echocardiogr 2008; 21: 828-833.

2. Egendy IY, Conti CR. Caseous calcification of the mitral annulus: a review. Clin Cardiol 2013; 36: E27-31.

3. Carpentier AF, Pellerin M, Fuzellier JF, et al. Extensive calcification of the mitral valve anulus: pathology and surgical management. J Thorac Cardiovasc Surg 1996; 111: 718-729.

4. Goodman HB, Dorney ER. Marfan's syndrome with massive calcification of the mitral annulus at age twenty-six. Am J Cardiol 1969; 24: 426-431.

5. Correale M, Deluca G, Ieva R, et al. Spontaneous resolution of a caseous calcification of the mitral annulus. Clinics 2009; 64: 1130-1132.

6. Mallat N, Limeme M, Zaghouani $\mathrm{H}$, et al. Caseous calcification of the mitral annulus on MDCT: a rare intracardiac mass. Acta Radiol Short Rep 2013; 2: 2047981613502177.

7. Garcia-Ibarrondo N, Lang RM. Caseous calcification of the mitral annulus, a rare echocardiographic finding. Rev Esp Cardiol 2011; 64: 828-831.

8. Motwani M, Fairbairn TA, Jogiya R, et al. Caseous calcification of the mitral valve complicated by embolization, mitral regurgitation, and pericardial constriction. Eur Heart J Cardiovasc Imaging 2012; 13: 792.

9. Starzyk K, Kot A, Spałek M, et al. Caseous calcification of mitral annulus: malicious look and benign character Folia Cardiologica 2017; 12: 390-393.
10. Harpaz D, Auerbach I, Vered Z, et al. Caseous calcification of the mitral annulus: a neglected, unrecognized diagnosis. J Am Soc Echocardiogr 2001; 14: 825-831.

11. Marcì M, Lo Jacono F. Mitral regurgitation due to caseous calcification of the mitral annulus: two case reports. Cases J 2009; 2: 95.

12. Akram M, Hasanin AM. Caseous mitral annular calcification: Is it a benign condition? J Saudi Heart Assoc 2012; 24: 205-208.

13. Corre J, Leroux L, Coste P. Caseous necrosis of mitral annulus: a rare cause of stroke. Case Rep Cardiol 2013; 2013: 748241.

14. Nestico PF, Depace NL, Morganroth J, et al. Mitral annular calcification: clinical, pathophysiology, and echocardiographic review. Am Heart J 1984; 107: 989-996.

15. Shriki J, Rongey Ch, Ghosh B, et al. Caseous mitral annular calcifications: Multimodality imaging characteristics. World J Radiol 2010; 28: 143-147.

16. Alkadhi H, Leschka S, Prêtre R, et al. Caseous calcification of the mitral annulus. J Thorac Cardiovasc Surg 2005; 129: 1438-1440.

17. De Conti F, Corbetti F, De Conti G, et al. Unusual tumor-like calcification of the mitral annulus: diagnosis and tissue characterization by ultrasound, computed tomography and magnetic resonance imaging. Ital Heart J 2005; 6: 160-163.

18. McKernan NP, Culp WC Jr, Knight WL, et al. CASE 2 - 2012 intraoperative diagnosis and management of caseous calcification of the mitral annulus. J Cardiothorac Vasc Anesth 2012; 26: 327-332. 